\title{
Kesiapsiagaan Bencana Berbasis Komunitas Perkotaan
}

\author{
Aprilyanto ${ }^{*}$, Rio Khoirudin Apriyadi, Tri Winugroho, I Dewa Ketut Kerta Widana, \\ Wilopo \\ Program Studi Manajemen Bencana, Fakultas Keamanan Nasional, Universitas Pertahanan. \\ *Email: aprilyanto80@gmail.com
}

DOI: https://doi.org/10.33369/pendipa.5.3.284-291

\begin{abstract}
[Urban Community-based Disaster Preparedness] Geographical, hydrological, demographic, and sociological conditions of Indonesia make Indonesia's territory prone to disasters (natural, non-natural, and social). The history of disasters shows a trend of increasing the number of victims and types of disasters. Various efforts are needed in anticipating the possibility of a disaster that will occur, so that preventing risks, reducing risks or even eliminating disaster risks by reducing vulnerability and or increasing the limited capacity of the community is the simplest solution to the complexity of the disaster problem. Disaster risk is the probability of a potential disaster with the consequent damage being a key element. A threat (danger) only becomes a disaster if it affects vulnerable communities. The community is a key element in dealing with disasters, besides being the first to know about a disaster incident, the community is not only an object but also a subject that must be empowered in disaster management. This means that whatever efforts in disaster management must lead to the community. Strategies are needed to increase community resilience to an increasing number of disaster risks. Pre-disaster mitigation and preparedness activities are needed to reduce the vulnerability of a community and to protect the community whenever a disaster occurs. This research contributes to the current knowledge of the urban community preparedness index in terms of disaster preparedness. This descriptive quantitative research uses univariate analysis as the blade of analysis with a sample of 204 respondents who live in the DKI Jakarta area, and were selected randomly. This study uses primary data. Data collection was carried out through an online google form questionnaire directly to residents of DKI Jakarta Province. The results showed that the population of DKI Jakarta Province has various socio-economic characteristics, $77.94 \%$ of respondents have had disaster experience, $46.67 \%$ of the Material Preparedness Index, $82.52 \%$ of the Knowledge and Awareness Index for Preparedness, and 52.94\% of the Preparedness Index. Act. Therefore, disaster risk reduction requires the efforts of all stakeholders such as the community (individuals and communities), government agencies, non-governmental organizations (NGOs), and even the business world.
\end{abstract}

Keywords: Disaster Preparedness, Community Based, Urban Community.

\begin{abstract}
ABSTRAK
Kondisi Geografis, hidrologis, demografis, dan sosiologis Indonesia menjadikan wilayah Indonesia rawan terhadap bencana (alam, non alam, dan sosial). Sejarah kebencanaan menunjukkan adanya tren peningkatan jumlah korban dan jenis bencananya. Berbagai upaya sangat diperlukan dalam mengantisipasi kemungkinan bencana yang akan terjadi, sehingga, mencegah risiko, mengurangi risiko atau bahkan menghilangkan risiko bencana dengan mengurangi kerentanan dan atau meningkatkan kapasitas masyarakat yang terbatas adalah jalan keluar paling sederhana atas rumitnya masalah kebencanaan. Risiko bencana adalah probabilitas dari bencana yang potensial dengan kerusakan akibatnya merupakan elemen kunci. Ancaman (bahaya) hanya menjadi bencana jika berdampak pada masyarakat yang rentan. Masyarakat adalah elemen kunci dalam menghadapi bencana, disamping yang pertama kali mengetahui
\end{abstract}


kejadian bencana, Masyarakat selain sebagai obyek juga sebagai subyek yang harus diberdayakan dalam penanggulangan bencana. Artinya apapun upaya dalam penanggulangan bencana harus bermuara pada masyarakat. Strategi diperlukan untuk meningkatkan ketahanan masyarakat terhadap peningkatan jumlah bahaya risiko bencana. Kegiatan mitigasi dan kesiapsiagaan prabencana sangat diperlukan untuk mengurangi kerentanan suatu masyarakat dan untuk melindungi masyarakat setiap kali terjadi bencana. Penelitian ini berkontribusi pada pengetahuan terkini tentang indeks kesiapsiagaan masyarakat perkotaan dalam hal kesiapan menghadapi bencana. Penelitian kuantitatif deskriptif ini menggunakan analisa univariat sebagai pisau analisisnya dengan sampel berjumlah 204 responden yang berdomisili di wilayah DKI Jakarta, serta dipilih secara acak. Penelitian ini menggunakan data primer. Pengumpulan data dilakukan melaui kuesioner online Google Form secara langsung kepada penduduk Provinsi DKI Jakarta. Hasil penelitian menunjukkan bahwa penduduk Provinsi DKI Jakarta memiliki karakteristik sosial ekonomi yang beragam, 77,94\% responden telah memiliki pengalaman kebencanaan, 46,67\% Indeks Kesiapsiagaan Material, 82,52\% Indeks Pengetahuan dan Kesadaraan Kesiapsiagaan, dan 52,94\% Indeks Kesiapsiagaan Bertindak. Oleh karena itu, pengurangan risiko bencana membutuhkan upaya dari semua pemangku kepentingan seperti masyarakat (individu dan komunitas), instansi pemerintah, lembaga swadaya masyarakat (NGO), bahkan dunia usaha.

Kata kunci: Kesiapsiagaan Bencana, Berbasis Komunitas, Komunitas Perkotaan.

\section{PENDAHULUAN}

Kondisi geografis, hidrologis, demografis, dan sosiologis Indonesia menjadikan wilayah Indonesia rawan terhadap bencana (alam, non alam, dan sosial). Sejarah kebencanaan menunjukkan bahwa kejadian bencana dan korban meninggal akibat bencana terus mengalami peningkatan (Boccard, 2021).

Berbagai upaya sangat diperlukan dalam mengantisipasi kemungkinan bencana yang akan terjadi, sehingga mengurangi risiko, mencegah risiko atau bahkan menghilangkan risiko bencana (Maarif, 2011) dengan meningkatkan kapasitas masyarakat yang terbatas adalah jalan keluar paling sederhana atas rumitnya masalah kebencanaan.

Risiko bencana adalah probabilitas dari bencana yang potensial dengan kerusakan akibatnya merupakan elemen kunci. Ancaman (Bahaya) hanya menjadi bencana jika berdampak pada masyarakat yang rentan (Antronico, De Pascale, Coscarelli, \& Gullà, 2020). Masyarakat adalah elemen kunci dalam menghadapi bencana, disamping yang pertama kali mengetahui kejadian bencana, masyarakat juga merupakan korban terbesar dalam bencana serta merupakan end to end penanggulangan bencana. Artinya apapun upaya dalam penanggulangan bencana harus bermuara pada masyarakat (Maarif, 2012).

Strategi diperlukan untuk meningkatkan ketahanan masyarakat terhadap peningkatan jumlah ancaman bencana tersebut. Kegiatan mitigasi dan kesiapsiagaan prabencana diperlukan untuk mengurangi kerentanan masyarakat dan untuk melindungi masyarakat setiap kali terjadi bencana.

Pengurangan risiko bencana membutuhkan upaya dari semua pemangku kepentingan (Koem, 2019), seperti masyarakat (individu dan komunitas), instansi pemerintah, lembaga swadaya masyarakat (NGO), bahkan dunia usaha. Masyarakat berada di garis depan dalam hal pengurangan risiko bencana. Oleh karena itu, penting untuk memperhatikan bagaimana masyarakat berupaya mengurangi dan bersiap menghadapi bencana. Hal ini dikenal sebagai perilaku protektif (Lindell \& Perry, 2012) dan menjadi fokus penelitian ini.

Meskipun kesiapsiagaan bencana dan perilaku protektif telah menarik perhatian Indonesia dan Negara di seluruh dunia (Djalante, Garschagen, Thomalla, \& Shaw, 2017), hanya ada sedikit penelitian tentang kesiapsiagaan komunitas di perkotaan.

Bencana di wilayah perkotaan sangatlah bervariasi (Putri \& Bahar, 2020) dan erat kaitannya dengan faktor-faktor seperti: keterpaparan mereka terhadap bahaya, kerentanan masyarakat, karakteristik sosial ekonomi dan budaya mereka, aksesibilitas infrastruktur mereka, dan kapasitas mereka untuk merespons (Cutter, Ash, \& Emrich, 2016).

Wilayah perkotaan memiliki risiko bencana yang sangat beragam. Misalnya Daerah Khusus 
Ibukota Jakarta (DKI Jakarta), Berdasarkan IRBI BNPB, Provinsi DKI Jakarta disamping berpotensi terhadap ancaman bencana gempabumi, juga memiliki risiko bencana banjir dan bencana hidrometerologis lain yang cukup tinggi (BNPB, 2018).

Hal ini didasarkan oleh bencana banjir setiap tahunnya di provinsi ini. Berdasarkan rekapitulasi data banjir Provinsi DKI Jakarta pada 1 Januari 2020 terdapat 157 Kelurahan (60\%) terdampak akibat bencana banjir (Nisa, 2020).

Oleh karena itu penelitian dengan judul "Kesiapsiapsiagaan Bencana Berbasis Komunitas Perkotaan" penting dilaksanakan. Hal ini mengantisipasi potensi multi bencana disaat pandemi Covid-19 (Apriyadi \& Amelia, 2020).

Penelitian ini berkontribusi pada pengetahuan terkini tentang gambaran kesiapsiagaan masyarakat perkotaan dalam hal persiapan menghadapi bencana.

\section{METODE PENELITIAN}

Jenis Penelitian dan Metode Analisis

Penelitian kuantitatif deskriptif ini menggunakan analisa univariat sebagai pisau analisisnya terhadap data primer (Bungin, 2010) kesiapsiagaan masyarakat perkotaan dalam hal persiapan menghadapi bencana.

\section{Lokasi dan Waktu Penelitian}

Penelitian dilaksanakan di Provinsi DKI Jakarta pada bulan Oktober - Desember 2020.

\section{Populasi dan Sampel Penelitian}

Populasi adalah totalitas atas objek yang diteliti (Bungin, 2017). Populasi penelitian ini adalah penduduk DKI Jakarta yang berjumlah 10.557.810 Penduduk.

Sampel adalah proporsi atas populasi secara karakteristik dan jumlah. (Anshori \& Iswati, 2009). Penelitian ini melibatkan 204 responden secara simple random sampling agar setiap komponen populasi mempunyai peluang sama menjadi (Margono, 2010) yang dihitung atas populasi menggunakan rumus Slovin (Amirin, 2011) dengan derajat signifikansi 93\% (atau eror

7\%), sebagai berikut: $\quad n=\frac{N}{1+N \cdot d^{2}}=$ $\frac{10.557 .810}{1+10.557 .810 \cdot(0,07)^{2}}=204$ Responden.

Teknik Pengumpulan Data
Pengumpulan data dilakukan melalui kuesioner online google form atas pertanyaan tertulis untuk dijawab oleh responden (Sugiyono, 2017).

\section{HASIL DAN PEMBAHASAN}

Deskripsi Karakteristik Responden

Karakteristik Demografi dan Sosial Ekonomi Komunitas Perkotaan terdiri atas 6 variabel (Tabel 1).

Tabel 1. Karakteristik Demografi dan Sosial Ekonomi Komunitas Perkotaan

\section{Karakteristik Demografi Jumlah dan Sosial Ekonomi (Persentase)} Komunitas Perkotaan

\begin{tabular}{cl}
\hline & $\mathbf{N}=\mathbf{2 0 4}$ \\
\hline Jenis Kelamin & \\
Laki-laki & $126(61,76)$ \\
Perempuan & $78 \quad(38,24)$ \\
\hline
\end{tabular}

\section{Kelompok Usia}

$\begin{array}{ll}0-15 \text { Tahun } & 0 \quad(0,00) \\ 16-20 \text { Tahun } & 4(1,96) \\ 21-25 \text { Tahun } & 24(11,76) \\ 26-30 \text { Tahun } & 25(12,25) \\ 31-35 \text { Tahun } & 35(17,16) \\ 36-40 \text { Tahun } & 36(17,65) \\ 41-45 \text { Tahun } & 58(28,43) \\ 46-50 \text { Tahun } & 15(7,35) \\ 51-55 \text { Tahun } & 6(2,64) \\ 56-60 \text { Tahun } & 1(0,49) \\ >60 \text { Tahun } & 0(0,00)\end{array}$

\section{Tingkat Pendidikan}

$\begin{array}{lll}\text { Tidak Pernah Sekolah / } & 0 & (0,00) \\ \text { Tidak Tamat SD } & \end{array}$

SD $1 \quad(0,49)$

SMP $2(0,98)$

SMA $31 \quad(15,20)$

D1 $0 \quad(0,00)$

D3 $12 \quad(5,83)$ 


\begin{tabular}{lll}
\hline S1 & 113 & $(55,39)$ \\
S2 & 42 & $(20,59)$ \\
S3 & 3 & $(1,47)$ \\
\hline
\end{tabular}

\section{Status Pernikahan}

Menikah

$158(77,45)$

Belum Menikah

$42(20,59)$

Bercerai

$4 \quad(1,96)$

\begin{tabular}{ll}
\hline Pekerjaan & \\
Pedagang & $16(7,84)$ \\
PNS/ Pegawai BUMN & $95(46,57)$ \\
Pegawai Swasta & $61(29,91)$ \\
Buruh & $9(4,41)$ \\
Ibu Rumah Tangga & $15(7,35)$ \\
Tidak Bekerja & $8(3,92)$
\end{tabular}

\section{Penghasilan Bulanan}

$\leq$ Rp. 2.000 .000

$22(10,78)$

Rp. 2.000 .000 s.d Rp.

5.000 .000

Rp. 5.000 .001 s.d

$42(20,59)$

10.000 .000

$110(53,92)$

Rp.10.000.001 s.d

$29(14,22)$

Rp.50.000.000

$\geq$ Rp. 50.000 .001

$1 \quad(0,49)$

\begin{tabular}{ll}
\hline $\begin{array}{l}\text { Jumlah Tanggungan } \\
\text { Keluarga } \\
\text { 1 Orang }\end{array}$ & $48(23,53)$ \\
2 Orang & $54(26,47)$ \\
3 Orang & $52(25,49)$ \\
4 Orang & $38(18,63)$ \\
5 Orang & $10(4,90)$ \\
6 Orang & $1 \quad(0,49)$ \\
$\geq 7$ Orang & $1 \quad(0,49)$ \\
\hline
\end{tabular}

Berdasarkan tabel 1 diatas diketahui bahwa 4 responden berusia $16-20$ tahun (1,96\%), 24 responden berusia $21-25$ tahun $(11,76 \%), 25$ responden berusia 26 - 30 tahun $(12,25 \%), 35$ responden berusia $31-35$ tahun $(17,16 \%), 36$ responden berusia 36 - 40 tahun $(17,65 \%), 58$ responden berusia $41-45$ tahun $(28,43 \%), 15$ responden berusia $46-50$ tahun $(7,35 \%), 6$ responden berusia 51 - 55 tahun $(2,94 \%), 1$ responden berusia $56-60$ tahun $(0,49 \%)$.

Berdasarkan data yang diperoleh terkait karakteristik tingkat pendidikan responden menggambarkan bahwa 1 responden $(0,49 \%)$ mempunyai tingkat pendidikan SD, 2 responden $(0,98 \%)$ mempunyai tingkat pendidikan SMP, 31 responden $(15,20 \%)$ mempunyai tingkat pendidikan SMA, 12 responden $(5,88 \%)$ mempunyai tingkat pendidikan D3, 113 responden $(55,39 \%)$ mempunyai tingkat pendidikan S1, 42 responden $(20,59 \%)$ mempunyai tingkat pendidikan $\mathrm{S} 2,3$ responden $(1,47 \%)$ mempunyai tingkat pendidikan S3.

Berdasarkan variabel pekerjaan terdapat 16 responden $(7,84 \%)$ bekerja sebagai pedagang, 95 responden (46,57\%) bekerja sebagai PNS/ Pegawai BUMN, 61 responden $(29,91 \%)$ bekerja sebagai Pegawai Swasta, 9 responden $(4,41 \%)$ bekerja sebagai Buruh, 15 responden $(7,35 \%)$ bekerja sebagai Ibu Rumah Tangga, 8 responden (20\%) tidak bekerja/ masih mencari pekerjaan.

Berdasarkan variabel penghasilan bulanan maka didapatkan bahwa 22 responden $(10,78 \%)$ mempunyai penghasilan kurang dari Rp.2000.000, 42 responden (20,59\%) mempunyai rentang penghasilan Rp. 2.000.000 s.d Rp. 5.000.000, 110 responden $(53,92 \%)$ mempunyai rentang penghasilan Rp. 5.000.001 s.d $10.000 .000,29$ responden $(14,22 \%)$ mempunyai rentang penghasilan Rp.10.000.001 s.d Rp.50.000.000, 1 responden $(0,49 \%)$ mempunyai penghasilan di atas Rp. 50.000.001.

Indeks variabel jumlah tanggungan keluarga responden menggambarkan bahwa terdapat 48 responden $(23,53 \%)$ mempunyai tanggungan 1 orang, 54 responden $(26,47 \%)$ mempunyai tanggungan 2 orang, 52 responden $(25,49 \%)$ mempunyai tanggungan 3 orang, 38 responden $(18,63 \%)$ mempunyai tanggungan 4 orang, 10 responden $(4,90 \%)$ mempunyai tanggungan 5 orang, 1 responden $(0,49 \%)$ mempunyai tanggungan 6 orang, 1 responden $(0,49 \%)$ mempunyai tanggungan $\geq 7$ orang.

Deskripsi Pengalaman Kebencanaan Responden 
Hasil analisis menunjukkan bahwa terdapat 159 responden $(77,94 \%)$ pernah mengalami kejadian bencana (tabel 2).

Tabel 2. Pengalaman Kebencanaan

\begin{tabular}{lcc}
\hline $\begin{array}{l}\text { Pengalaman } \\
\text { Kebencanaan }\end{array}$ & $\begin{array}{c}\text { Ya } \\
(\boldsymbol{\%})\end{array}$ & $\begin{array}{c}\text { Tidak } \\
(\mathbf{\%})\end{array}$ \\
\hline $\begin{array}{l}\text { Apakah anda pernah } \\
\text { mengalami kejadian } \\
\text { bencana alam? }\end{array}$ & 77,94 & 22,06 \\
\hline
\end{tabular}

Kejadian bencana yang dialami 159 responden di atas adalah banjir, tanah longsor, kekeringan/ cuaca ekstrim, ROB, gempa bumi.

\section{Deskripsi Indeks Kesiapsiagaan Material}

Data kuesioner variabel Indeks Kesiapsiagaan Material berisi 5 pertanyaan yang dihitung berdasarkan distribusi responden, bernilai 0 jika jawaban salah, dan 1 jika benar (tabel 3).

Tabel 3. Indeks Kesiapsiagaan Material

\begin{tabular}{|c|c|c|c|}
\hline No & $\begin{array}{l}\text { Pertanyaan } \\
\text { Kesiapsiagaaan } \\
\text { Material }\end{array}$ & $\begin{array}{c}\text { Ya } \\
(\%)\end{array}$ & $\begin{array}{c}\text { Tidak } \\
(\%)\end{array}$ \\
\hline 1 & $\begin{array}{l}\text { Apakakah anda } \\
\text { memiliki lampu } \\
\text { darurat atau senter? }\end{array}$ & 84,80 & 15,20 \\
\hline 2 & $\begin{array}{l}\text { Apakah anda } \\
\text { memiliki cadangan } \\
\text { makanan dan air } \\
\text { yang tersedia untuk } \\
\text { anggota keluarga } \\
\text { dalam waktu } 72 \text { jam? }\end{array}$ & 71,08 & 28,92 \\
\hline 3 & $\begin{array}{l}\text { Apakah anda } \\
\text { memiliki } \\
\text { perlengkapan } \\
\text { darurat? }\end{array}$ & 39,22 & 60,78 \\
\hline 4 & $\begin{array}{l}\text { Apakah anda } \\
\text { memiliki alat } \\
\text { komunikasi/radio } \\
\text { menggunakan } \\
\text { baterai? }\end{array}$ & 32,35 & 67,65 \\
\hline 5 & $\begin{array}{l}\text { Apakah anda } \\
\text { memiliki alat } \\
\text { pemadam } \\
\text { kebakaran? }\end{array}$ & 5,88 & 94,12 \\
\hline
\end{tabular}

Distribusi Jawaban responden atas pertanyaan 1 mengenai apakah anda memiliki lampu darurat atau senter menunjukkan bahwa 173 responden $(84,80 \%)$ memiliki lampu darurat atau senter dan 31 responden lainnya $(15,20 \%)$ tidak memiliki lampu darurat atau senter. Hal ini menunjukkan masyarakat komunitas perkotaan memiliki kesadaran bahwa lampu darurat atau senter diperlukan pada saat keadaan darurat bencana.

Pertanyaan 2 terkait apakah anda memiliki cadangan makanan dan air yang tersedia untuk anggota keluarga dalam waktu 72 jam menunjukkan bahwa 145 responden $(71,08 \%)$ memiliki cadangan makanan dan air untuk anggota keluarga dalam waktu 72 jam dan dan 59 responden lainnya $(28,92 \%)$ tidak memiliki cadangan makanan dan air untuk anggota keluarga dalam waktu 72 jam.

Hal ini menunjukkan masyarakat komunitas perkotaan telah memiliki kesiapsiagaan apabila terjadi bencana, mereka telah tersedia bahan pokok makanan dan air pada masa darurat (72 jam).

Pertanyaan 3 mengenai apakah anda memiliki perlengkapan darurat, jawaban responden menggambarkan bahwa 80 responden $(39,22 \%)$ memiliki perlengkapan darurat, sedangkan 124 responden lainnya $(60,78 \%)$ tidak memiliki perlengkapan darurat. Hal ini menunjukkan sebagian besar masyarakat komunitas perkotaan belum memiliki perlengkapan darurat dalam menghadapi bencana karena oleh masyarakat dianggap belum menjadi kebutuhan prioritas.

Pertanyaan 4 mengenai apakah anda memiliki alat komunikasi/ radio menggunakan baterai menunjukkan bahwa 66 responden $(32,35 \%)$ memiliki alat komunikasi/ radio yang siap digunakan dalam keadaan darurat, sedangkan 138 responden lainnya $(67,65 \%)$ tidak memiliki alat komunikasi/ radio komunikasi darurat. Hal ini bertolak belakang terhadap pentingnya alat komunikasi darurat dalam kesiapsiagaan bencana. Penelitian ini membuktikan bahwa sebagian besar masyarakat komunitas perkotaan belum memiliki kesadaran pentingnya alat komunikasi darurat pada saat bencana.

Pertanyaan 5 mengenai apakah anda memiliki alat pemadam kebakaran 
menggambarkan bahwa 12 responden $(5,88 \%)$ memiliki alat pemadam kebakaran, sedangkan 192 responden lainnya $(94,12 \%)$ tidak memiliki alat pemadam kebakaran.

Penelitian ini menunjukkan sebagian besar masyarakat komunitas perkotaan belum memiliki apar terkait kesiapsiagaan menghadapi bencana kebakaran. Hal ini dikarenakan apar belum menjadi kebutuhan prioritas oleh masyarakat.

Berdasarkan tabel 3 diatas dapat diketahui bahwa score yang tertinggi dari pertanyaan Indeks Kesiapsiagaan Material adalah dari pertanyaan tentang kepemilikan lampu darurat atau senter pada saat darurat dengan score 84,80, sedangkan score yang terendah adalah dari pertanyaan tentang kepemilikan alat pemadam kebakaran dengan score 5,88.

\section{Deskripsi Indeks Pengetahuan dan Kesadaraan Kesiapsiagaan \\ Data kuesioner variabel Indeks Pengetahuan dan Kesadaraan Kesiapsiagaan berisi 3 pertanyaan yang dihitung berdasarkan distribusi responden, bernilai 0 jika jawaban salah, dan 1 jika benar (tabel 4).}

Tabel 4. Indeks Pengetahuan dan Kesadaraan Kesiapsiagaan

\begin{tabular}{|c|c|c|c|}
\hline No & $\begin{array}{c}\text { Pertanyaan } \\
\text { Pengetahuan dan } \\
\text { Kesadaraan } \\
\text { Kesiapsiagaan }\end{array}$ & $\begin{array}{c}\text { Ya } \\
(\%)\end{array}$ & $\begin{array}{c}\text { Tidak } \\
(\%)\end{array}$ \\
\hline 6 & $\begin{array}{l}\text { Tahukah anda } \\
\text { bagaimana cara } \\
\text { mematikan gas, } \\
\text { listrik atau air rumah } \\
\text { anda? }\end{array}$ & 98,04 & 1,96 \\
\hline 7 & $\begin{array}{l}\text { Apakah anda tahu } \\
\text { cara / prosedur } \\
\text { evakuasi apartemen } \\
\text { / rumah anda dalam } \\
\text { keadaan darurat? }\end{array}$ & 83,33 & 16,67 \\
\hline 8 & $\begin{array}{l}\text { Tahukah anda di } \\
\text { mana tempat } \\
\text { berkumpul terdekat } \\
\text { dalam keadaan } \\
\text { darurat? }\end{array}$ & 66,18 & 33,82 \\
\hline
\end{tabular}

Pertanyaan 6 menunjukkan bahwa terdapat 200 responden $(98,04 \%)$ memiliki pengetahuan tentang bagaimana cara mematikan gas, listrik atau air rumah sendiri, sedangkan 4 responden lainnya $(1,96 \%)$ tidak memiliki pengetahuan tersebut.

Pertanyaan 7 menunjukkan bahwa terdapat 170 responden $(83,33 \%)$ memiliki pengetahuan tentang cara / prosedur evakuasi apartemen / rumah dalam keadaan darurat, sedangkan 34 responden lainnya $(16,67 \%)$ tidak memiliki pengetahuan tersebut.

Pertanyaan 8 menunjukkan bahwa terdapat 135 responden $(66,18 \%)$ memiliki pengetahuan tentang tempat berkumpul terdekat dalam keadaan darurat?, 69 responden lainnya $(33,82$ $\%)$ tidak memiliki pengetahuan tersebut.

Berdasarkan tabel 4 diatas dapat diketahui bahwa score yang tertinggi dari pertanyaan Indeks Pengetahuan dan Kesadaraan Kesiapsiagaan adalah pertanyaan tentang pengetahuan bagaimana cara mematikan gas, listrik atau air rumah anda dengan score 98,04, sedangkan score yang terendah adalah pertanyaan tentang pengetahuan di mana tempat berkumpul terdekat dalam keadaan darurat dengan score 66,18.

Hasil ini menunjukkan bahwa sebagian besar responden memiliki pengetahuan tentang kesiapsiagaan bencana dengan baik, terkait cara mematikan gas, listrik atau air dan pengetahuan prosedur evakuasi serta tempat berkumpul terdekat dalam keadaan darurat.

\section{Deskripsi Indeks Kesiapsiagaan Bertindak}

Data kuesioner variabel Indeks Pengetahuan dan Kesadaraan Kesiapsiagaan berisi 3 pertanyaan yang dihitung berdasarkan jawaban responden, bernilai 0 jika jawaban salah, dan 1 jika benar (tabel 4).

Data kuesioner variabel Indeks Kesiapsiagaan Bertindak berisi 3 pertanyaan yang dihitung berdasarkan distribusi responden, bernilai 0 jika jawaban salah, dan 1 jika benar (tabel 5).

\section{Tabel 5. Indeks Kesiapsiagaan Bertindak}

\begin{tabular}{llcc}
\hline No & $\begin{array}{c}\text { Pertanyaan } \\
\text { Kesiapsiagaan } \\
\text { Bertindak }\end{array}$ & $\begin{array}{c}\text { Ya } \\
(\%)\end{array}$ & $\begin{array}{c}\text { Tidak } \\
(\boldsymbol{\%})\end{array}$ \\
\hline 9 & $\begin{array}{l}\text { Apakah anda pernah } \\
\text { berpartisipasi dalam } \\
\text { pelatihan }\end{array}$ & 66,18 & 33,82 \\
\hline
\end{tabular}




\begin{tabular}{|c|c|c|c|}
\hline \multirow{5}{*}{10} & \multicolumn{3}{|l|}{ kebencanaan atau } \\
\hline & latihan darurat? & & \\
\hline & Pernahkah anda & 79,41 & 20,59 \\
\hline & berdiskusi dengan & & \\
\hline & kerabat, teman atau & & \\
\hline & kolega Anda tentang & & \\
\hline & apa yang harus & & \\
\hline & dilakukan jika & & \\
\hline & terjadi bencana? & & \\
\hline \multirow[t]{9}{*}{11} & Apakah anda & 13,24 & 86,76 \\
\hline & seorang Relawan & & \\
\hline & Bencana atau & & \\
\hline & anggota Palang & & \\
\hline & Merah Indonesia, & & \\
\hline & BNPB, BPBD, & & \\
\hline & CERT, atau & & \\
\hline & organisasi terkait & & \\
\hline & bencana lainnya? & & \\
\hline
\end{tabular}

Pertanyaan 9 menunjukkan bahwa 135 responden $(66,18 \%)$ pernah berpartisipasi dalam pelatihan kebencanaan atau latihan darurat, sedangkan 69 responden lainnys $(33,82 \%)$ belum pernah mengikuti pelatihan tersebut.

Pertanyaan 10 menggambarkan bahwa 162 responden $(79,41 \%)$ pernah berdiskusi dengan kerabat, teman atau kolega tentang apa yang harus dilakukan jika terjadi bencana, sedangkan 42 responden lainnya $(20,59 \%)$ mengaku belum pernah berdiskusi terkait hal tersebut.

Pertanyaan 11 tentang apakah anda seorang relawan bencana atau anggota palang merah indonesia, BNPB, BPBD, CERT, atau organisasi terkait bencana lainnya, jawaban responden menunjukkan bahwa 27 responden $(13,24 \%)$ merupakan seorang relawan bencana, sedangkan 177 responden $(86,76)$ bukan merupakan seorang relawan bencana.

Berdasarkan tabel 5 diatas dapat diketahui bahwa score yang tertinggi dari pertanyaan Indeks Kesiapsiagaan Bertindak adalah pertanyaan tentang pernahkah anda berdiskusi dengan kerabat, teman atau kolega Anda tentang apa yang harus dilakukan jika terjadi bencana dengan score 79,41, sedangkan score yang terendah adalah pertanyaan tentang apakah anda seorang Relawan Bencana atau anggota Palang Merah Indonesia, BNPB, BPBD, CERT, atau organisasi terkait bencana lainnya dengan score 13,24 .
Dalam penelitian ini, walaupun mayoritas responden bukan merupakan relawan bencana, namun komunitas masyarakat perkotaan telah memiliki kesadaran akan pentingnya tindakan dalam kesiapsiagaan bencana (action).

Hasil olah data penelitian menunjukkan bahwa penduduk Provinsi DKI Jakarta memiliki karakteristik sosial ekonomi yang beragam, $77,94 \%$ responden memiliki pengalaman kebancanaan, 46,67\% Indeks Kesiapsiagaan Material, 82,52\% Indeks Pengetahuan dan Kesadaraan Kesiapsiagaan, dan 52,94\% Indeks Kesiapsiagaan Bertindak.

\section{KESIMPULAN} berikut:

Kesimpulan atas hasil penelitian ini sebagai

1. Responden Provinsi DKI Jakarta memiliki Karakteristik Demografi dan Sosial Ekonomi yang beragam, dalam penelitian ini keberagaman tersebut terdiri atas 6 variabel yaitu jenis kelamin, kelompok usia, tingkat pendidikan, status pernikahan, pekerjaan, penghasilan bulanan dan jumlah tanggungan keluarga.

2. Pengetahuan terkini tentang indeks kesiapsiagaan masyarakat perkotaan dalam hal kesiapan menghadapi bencana dalam kategori cukup baik dengan rerata $65,01 \%$, dimana digambarkan bahwa $77,94 \%$ responden memiliki pengalaman kebencanaan, 46,67\% indeks kesiapsiagaan material, $82,52 \%$ indeks pengetahuan dan kesadaraan kesiapsiagaan, dan 52,94\% indeks kesiapsiagaan bertindak.

3. Pengurangan risiko bencana membutuhkan upaya dari semua pemangku kepentingan seperti masyarakat (individu dan komunitas), instansi pemerintah, lembaga swadaya masyarakat (NGO), bahkan dunia usaha. Hal ini dikarenakan risiko bencana di wilayah perkotaan sangatlah bervariasi dan erat kaitannya dengan faktor-faktor seperti: keterpaparan mereka terhadap bahaya, kerentanan masyarakat, karakteristik sosial ekonomi dan budaya mereka, aksesibilitas infrastruktur mereka, dan kapasitas mereka untuk merespons.

DAFTAR PUSTAKA

Amirin, T. (2011). Populasi Dan Sampel 
Penelitian 4: Ukuran Sampel Rumus Slovin. Jakarta: Penerbit Erlangga.

Anshori, M., \& Iswati, S. (2009). Metodologi Penelitian Kuantitatif. Surabaya: Pusat Penerbitan dan Percetakan UNAIR (AUP).

Antronico, L., De Pascale, F., Coscarelli, R., \& Gullà, G. (2020). Landslide risk perception, social vulnerability and community resilience: The case study of Maierato (Calabria, southern Italy). International Journal of Disaster Risk Reduction, 46, 101529.

https://doi.org/10.1016/j.ijdrr.2020.101529

Apriyadi, R. K., \& Amelia, R. (2020). Tingkat Pengetahuan Kesiapsiagaan Resiko Bencana Tsunami disaat Pandemi Covid19. PENDIPA Journal of Science Education, 5(1), 56-62. https://doi.org/10.33369/pendipa.5.1.56-62

BNPB. (2018). Indeks Risiko Bencana Indonesia Tahun 2018. Jakarta: Badan Nasional Penanggulangan Bencana.

Boccard, N. (2021). Analysis of trends in disaster risk. International Journal of Disaster Risk Reduction, $\quad 53, \quad 101989$. https://doi.org/10.1016/j.ijdrr.2020.101989

Bungin, B. (2010). Metodologi penelitian kuantitatif: komunikasi, ekonomi, dan kebijakan publik serta ilmu-ilmu sosial lainnya. Jakarta: Kencana Prenada Media Group.

Bungin, B. (2017). Metodologi Penelitian Kuantitatif. Jakarta: Kencana.

Cutter, S. L., Ash, K. D., \& Emrich, C. T. (2016). Urban-Rural Differences in Disaster Resilience. Annals of the American Association of Geographers, 106(6), 12361252.

https://doi.org/10.1080/24694452.2016.119 4740
Djalante, R., Garschagen, M., Thomalla, F., \& Shaw, R. (2017). Disaster Risk Reduction in Indonesia. Springer.

Koem, S. (2019). Membangun Ketahanan Berbasis Komunitas dalam Mengurangi Risiko Bencana di Desa Pilomonu Kabupaten Gorontalo. Jurnal Pengabdian Pada Masyarakat, 4(2), 211-222. https://doi.org/10.30653/002.201942.143

Lindell, M. K., \& Perry, R. W. (2012). The Protective Action Decision Model: Theoretical Modifications and Additional Evidence. Risk Analysis, 32(4), 616-632. https://doi.org/10.1111/j.15396924.2011.01647.x

Maarif, S. (2011). Meningkatkan Kapasitas masyarakat dalam mengatasi risiko bencana kekeringan. Jurnal Sains Dan Teknologi Indonesia, 13(2), 65-73.

Maarif, S. (2012). Pikiran dan Gagasan Penanggulangan Bencana di Indonesia. Jakarta: Badan Nasional Penanggulangan Bencana.

Margono, S. (2010). Metode Penelitian Pendidikan. Jakarta: Rineka Cipta.

Nisa, K. (2020). Rekapitulasi Data Banjir Dki Jakarta dan Penanggulangannya. http://statistik.jakarta.go.id/rekapitulasidata-banjir-dki-jakarta-danpenanggulangannya-tahun-2020/

Putri, F. D., \& Bahar, F. (2020). Analisis Layanan Jakarta Siaga 112 Dalam Mendukung Penanganan Bencana Di DKI Jakarta. Jurnal Manajemen Bencana (JMB), 6(1). https://doi.org/10.33172/jmb.v6i1.614

Sugiyono, P. D. (2017). Metode Penelitian Bisnis: Pendekatan Kuantitatif, Kualitatif, Kombinasi, dan R\&D. Bandung : Penerbit CV. Alfabeta. 